\title{
BIOGRAFI SYEKH MUHAMMAD ARSYAD AL-BANJARI
}

\author{
Herlina \\ Email : 2010128320002@mhs.ulm.ac.id \\ Program Studi Pendidikan IPS Fakultas Keguruan dan Ilmu Pendidikan \\ Universitas Lambung Mangurat \\ Banjarmasin
}

\begin{abstract}
Abstrak
Syekh Muhammad Arsyad Al-Banjari adalah Ulama terkemuka asal Martapura, Kalimantan Selatan. Beliau dilahirkan pada15 Shafar $1122 \mathrm{H}$ atau 17 Maret $1710 \mathrm{M}$ di Desa Lok Gabang, dan beliau meninggal atau wafat pada tanggal 3 oktober $1812 \mathrm{M}$ yang dimakamkan di Desa Kalampayan, Martapura Kalimantan Selatan. Beliau memiliki otak yang cemerlang dan memiliki keterampilan yang produktif. Beliau dibawa oleh Sultan Tahlilullah ke istana untuk menuntut ilmu. Kurang lebih 30 tahun beliau menuntut ilmu di mekkah dan 5 tahun dimadinah. Sepulang dari tanah suci beliau mendirikan pusat pengajaran dan pendidikan agama islam di martaputa tempat yang baru yang dikenal dengan sebutan Dalam Pagar. Selain itu beliau juga berdakwah kepada msyarakat umum dari perkotaan hingga polosok desa terpencil. Hal tersebut bertjuan agar masyarakat mendapatkan pengetahuan agamanya serta mengamalkannya dalam kehidupan sehari-hari. Syekh Muhammad Arsyad al-Banjari ini memiliki peranan yang sangat penting dalam kehidupan masyarakat. Upaya-upaya beliau memang luar biasa yang tak kenal lelah demi mewujudkan masyarakatnya agar memilki pengetahuan agama yang baik.
\end{abstract}

\section{PENDAHULUAN}

Seorang ulama yang bernama Muhammad Arsyad Al-Banjari adalah seorang terkemuka yang berasal dari Martapura Kalimantan Selatan. Yang lahir Pada tahun 1122 $\mathrm{H}$ atau 17 Maret $1710 \mathrm{M}$ dan wafat pada tahun $1812 \mathrm{M}$ di umur ke 105 tahun. Beliau berasal dari keluarga yang taat dalam beragama, sejak kecil beliau sudah diajarkan oleh ayah beliau tentang agama, sehingga di usia yang masih kecil beliau sudah fasih membaca ayat Al-Qur'an, beliau juga anak kecil yang memilki kecerdasan yang luar biasa dan memiliki keterampilan yang produktif seperti melikus, sehingga karya yang dihasilkannya membuat orang terpukau melihatnya. Sejak kecil beliau dibawa oleh Sultan Tahlilullah untuk dididik di tanah suci, beliau menuntut ilmu di tanah suci selama 35 tahun. Setelah banyak menimba ilmu ditanah suci, Muhammad Arsyad telah diberikan izin oleh para guru-guru beliau untuk memakai gelar syekh itu mulai perjuangannya pada saat menyebarkan ajaran-ajaran islam ditanah airnya yaitu 
Martapura, Kalimantan Selatan. Tersebarnya agama islam ke berbagai pelosok daerah terpencil merupakan suatu usaha yang dilakukan oleh Muhammad Arsyad dan seorang cucunya yang telah memiliki ilmu pengetahuan dari hasil didikan muhammad arsyad. Oleh karena itu, mereka pergi berdakwah ke tempat-tempat seperti Pagatan, Taniran, Amuntai, Marabahan, dan Martapura. Banyak aktivitas Muhammad Arsyad yang di arahkan demi terlaksananya ajaran-ajaran islam dalam kehidupan masyarakat, yaitu melaksanakan pengkedetan ulama semacam pesantren di Dalam pagar yang bertujuan untuk ulama agar memahami ajaran-ajaran islam dan sekaligus mampu mengamalkannya. Beliau telah memberikan berbagai sumbangan ilmu kepada masyarakat, sejak tahun 1772 M di Kalimantan Selatan beliau berdakwah bil hal dengan membangun sebuah institusi pendidikan untuk masyarakat sekitar atau ulama, kemudian beliau juga menjadi penasehat kerajaan Banjar dalam bidang keagamaan, dalam bidang ini beliau mewujudkan untuk mengubah suatu kebodohan yang dimiliki masyarakat islam menjadi muslim yang taat. Kurang lebih 40 tahun beliau melakukan penyebaran islam di Kalimantan selatan dan setelah itu beliau wafat pada tahun $1812 \mathrm{M}$.

\section{METODE PENELITIAN}

Metode dalam Penelitian ini adalah metode kualitatif, sebagaimana yang disampaikan oleh Bogdandan Taylor (Dalam Moleong, 2005) bahwa penelitian kualitatif sebagai prosedur penelitian yang nantinya akan menghasilkan sebuah deskriftif yaitu berupa penjelasan dari berbagai dokumen-dokumen atau dari jurnaljurnal ilmiah yang di temukan.

\section{PEMBAHASAN}

Syekh Muhammad Arsyad Al-Banjari lahir di desa Lok Gabang, Martapura Kalimantan Selatan pada tanggal 17-05-1710 M. dan beliau meninggal atau wafat pada tanggal 3-10-1812 M yang dimakamkan di Desa Kalampayan, Martapura Kalimantan Selatan. Muhammad Arsyad pada waktu kecil diberi nama oleh orangtuanya bernama Muhammad Ja'far lalu setelah menjelang remaja kemudian diberi nama Muhammad Arsyad. Sejak kecil, beliau sudah memiliki kecerdesan yang luar biasa dan memiliki akhlak yang mulia serta terpuji. Beliau pertama mendapatkan pendidikan keagamaan dari seorang ayahnya yang mana ia sudah fasih dalam membaca ayat Al-Qur'an ketika 
berusia tujuh tahun. Beliau juga gemar menulis dan melukis sehingga apabila orang yang melihat hasil karyanya tersebut maka akan terpukau dengan hasil karyanya itu, hal tersebutlah yang membuat Sultan Tahlilullah saat mengadakan suatu kunjungan kekampung-kampung, lalu beliau sempatkan ke kampung Lok Gabang untuk berkunjung ke tempat Muhammad Arsyad dan beliau saat itu sangat tertarik dengan hasil karya Muhammad Arsyad, lalu beliau berniat untuk merawat dan mendidik Muhammad Arsyad di istana. Kemudian Sultan Tahlilullah memohon izin kepada orang tua Muhammad Arsyad untuk mendidiknya di tanah suci, awalnya orang tuanya sangat enggan melepas putra pertamanya, namun dengan berbagai pertimbangan yaitu terhadap masa depan Muhammad Arsyad orang tuanya pun mengizinkan. Muhammad Arsyad Al-Banjari setelah di bawa oleh Sultan Tahlilullah mendapat suatu pendidikan di istana sehingga mencapai usia kurang lebih tiga puluh tahun. Setelah itu beliau dikawinkan dengan seorang perempuan yang sholehah bernama Tuan Bajut oleh Sultan Tahlilullah. Kemudian tidak lama setelah acara pernikahan Muhammad Arsyad ingin melanjutkan pendidikannya di Tanah Suci Mekah, oleh karena itu beliau meminta izin kepada istrinya yang mana pada saat itu sedang hamil anak pertama. Keinginan Muhammad Arsyad tersebut mendapatkan izin oleh istrinya. Maka setelah itu berngakatlah Muhammad Arsyad atas pembiayaan Sultan Tahlilullah dengan tujuan untuk menggapai cita-citanya menjadi lebih baik. Muhammad Arsyad selama menuntut ilmu ditanah suci menjalin persahabatan dengan 3 orang yang berasal dari negeri nusantara, orang-orang tersebut ialah Syekh Abdussamad Falimbani, Syekh Abdul Wahab Bugis, dan Syekh Abdurrahman Misri Bantani (Subiyakto, 2020).

Setelah kurang lebih 30 tahun menuntut ilmu dimekkah dan 5 tahun di madinah, lalu mereka berkeinginan untuk melanjutkan pendidikan ke Mesir, kemudian mereka menyampaikan keinginan mereka tersebut kepada Syekh Muhammad bin Sulaiman AlKurdi yang mana beliau adalah guru mereka, dan ternyata niat empat orang sahabat tersebut ditolak dan disarankan agar mereka segera kembali ke tanah air karena beliau mengatakan bahwa ilmu yang mereka dapat sudah memadai untuk berdakwah dan menegakkan syariat islam. Sebelum pulangnya mereka ke negara nusantara atau kampung halaman, mereka tersebut berniat untuk berhaji kembali ke Tanah Suci. Namun setelah itu, tak di duga Muhammad Arsyad bertemu dengan Adik nya yaitu Zainal Abidin yang sedang menunaikan ibadah haji. Zainal Abidin bercerita bahwa anak 
Muhammad Arsyad yaitu yang bernama Syarifah Putri sudah dewasa, oleh karena itu ketiga sahabat Muhammad Arsyad mendengar dan langsung mengajukan sebuah lamaran untuk menikahi anak perempuan beliau tersebut. Setelah dipikir-pikir Muhammad Arsyad memberikan keputusan dengan mengambil sebuah kebijakan dengan pengundian, hasil lamaran yang diterima adalah Syekh Abdul Wahab Bugis , Kemudian Setelah pernikahan itu, ke empat sahabat tersebut kembali ke Nusantara, yang tujuan pertamanya yaitu ke kampung halaman Syekh Abdussamad Al-Falimbani, kemudian mereka melanjutkan perjalanan ke Betawi yang mana kampung halaman Syekh Abdurrahman Misri Bantani. Sementara itu Muhammad Arsyad diminta untuk menetap di betawi oleh warga sekitarnya. Selama dikampung tersebut Muhammad Arsyad membetulkan arah kiblat masjid jembatan lima, mesjid luar batang, dan masjid pekajon. Setelah itu Muhammad Arsyad dan sahabatnya yaitu Abdul wahab Bugis melanjutkan perjalanan nya yaitu ke Martapura, Kalimantan Selatan. Mereka sampai disana pada bulan ramadhan $1186 \mathrm{H}$. setelah tiba ditempat, ternyata Sultan Tahlilullah seorang yang banyak membantu dan mendidiknya telah meninggal dunia, dan karena itulah digantikan oleh Sultan Tamjidillah I yang mana beliau adalah cucu dari Muhammad Arsyad. Saat tiba di kampung halaman, upaya yang dilakukan Muhammad Arsyad al-banjari yang pertama adalah membuat pengajian semacam pesantren, yang bertempat di sekitar 18 kilometer dari kota martapura yang dikenal sebagai kampung Dalam Pagar. Tidak sebatas membangun pengajian model pesantern, Muhammad Arsyad juga berdakwah ke daerah-daerah baik di perkotaan maupun kepelosok daerah terpencil. Muhammad Arsyad memilki banyak kitab yang menjadi pegangan umat muslim. Kitab-kitab tersebut iyalah kitab tauhid, kitab Fiqh, dan kitab Tasawuf. Perjuangan Muhammad Arsyad setelah itu dilanjutkan oleh pewaris keturunannya yang tersebar dinegara Asia tenggara. Ulama besar yang telah memberikan ilmunya untuk berbagai masyarakat ini telah meninggal atau wafat pada tanggal 6 Syawal $1227 \mathrm{H}$ di umur di 105 tahun dan jasadnya dimakamkan di Kalampayan. Martapura, Kalimantan Selatan

\section{SIMPULAN}

Syekh Muhammad Arsyad Al-Banjari adalah seorang tokoh karismatik ulama Banjar Kalimantan Selatan yang berperan besar dalam upaya memperbaiki kehidupan 
masyarakat dalam ilmu agama. Beliau lahir pada tanggal 15 Shafar $1122 \mathrm{H}$. dan telah meninggal dunia pada tanggal 3 oktober 1812 M yang dimakamkan di Desa Kalampayan. Sejak berusia kurang lebih tujuh tahun beliau sudah bisa bahkan fasih dalam mengucapan ayat-ayat Al-Qur'an yang di ajarkan oleh ayah nya sendiri. Dan sejak kecil beliau dibawa oleh Sultan Tahlilullah ke istana untuk menuntut ilmu karena beliau memiliki kecerdasan yang luar biasa dan memiliki keterampilan yang menarik. Setelah kurang lebih 30 tahun beliau menuntut ilmu dimekkah dan 5 tahun di madinah lalu beliau bersama 3 orang sahabat berkeinginan untuk melanjutkan menuntut ilmu di mesir, namun disarankan oleh guru mereka agar mereka segera kembali ke tanah air masing-masing saja untuk berdakwah dan menegakkan syariat islam. Sehabis beliau sampai di tanah air beliau mendirikan pusat pengajaran dan pendidikan agama islam bertempat yang bernama Dalam Pagar. Selain itu juga beliau aktif dalam berdakwah ke perkotaan hingga kepolosok terpencil. Upaya-upaya yang dilakukan Muhammad Arsyad sepulang dari Tanah air memang luar biasa dia tak kenal lelah demi masyarakatnya agar memilki pengetahuan agama yang baik serta dapat mengamalkannya.

\section{DAFTAR PUSTAKA}

Abdullah, A.R.H. (2016). Biografi Syekh Muhammad Arsyad Al-Banjari. Karya Bestari

Afdoli, A. (2018). Pemikiran Muhammad Arsyad Al-Banjari tentang Kearifan Lokal dalam Kitab Sabilal Muhtadin (Perspektif Maqashid Al-Syari'ah)

Arianti, A.(2017). Gerakan Pemurnian Islam Syekh Muhammad Arsyad Al-Banjari di Kalimantan Selatan.

Hadi, A. Sejarah Riwayat dan Mengenal Karangan Syekh Muhammad Arsyad AlBanjari.

Subiyakto, B.(2015). Syekh Muhammad Arsyad Al-Banjari: Upaya dan Ajaran Nilai Karakter dalam Pendidikan Ilmu Pengetahuan Sosial (Doctoral dissertation, Universitas Pendidikan Indonesia).

Suriadi, A. (2014). Syekh Muhammad Arsyad Al-Banjari dalam Dinamika Politik Kerajaan Banjar Abad XIX.

Yaqin, H. (2011). Syekh Muhammad Arsyad Al-Banjari Thought on Education. Journal of Indonesian Islam, 5(2), 335-352.

Zarkasyi, M. (2020). Syekh Muhammad Arsyad Al-Banjari, Ketokohan dan Sumbangnya. Jurnal Pengajian Melayu, 23(1), 185-218. 